Research Article

\title{
Deformation Response Research of the Existing Subway Tunnel Impacted by Adjacent Foundation Pit Excavation
}

\author{
Xin Dong, ${ }^{1}$ Ling Mei $\mathbb{D}^{1}{ }^{1}$ Shuyan Yang, ${ }^{1}$ and Liang $\mathrm{He}^{2}$ \\ ${ }^{1}$ School of Civil Engineering and Architecture, Jiangsu University of Science and Technology, Zhenjiang, Jiangsu 212100, China \\ ${ }^{2}$ School of Civil Engineering and Architecture, Changzhou Institute of Technology, Changzhou, Jiangsu 213032, China \\ Correspondence should be addressed to Ling Mei; mling530@163.com
}

Received 9 October 2021; Accepted 27 November 2021; Published 21 December 2021

Academic Editor: Ivan Giorgio

Copyright (c) 2021 Xin Dong et al. This is an open access article distributed under the Creative Commons Attribution License, which permits unrestricted use, distribution, and reproduction in any medium, provided the original work is properly cited.

The excavation of foundation pits is one of the most important factors causing changes to the initial stress state of its surrounding soil, thus affecting the safety of nearby existing subway tunnels. In order to study the deformation in metro lines induced by adjacent foundation pit excavation, a three-dimensional model based on an actual engineering case was established, and the deformation regulations of the retaining wall, surrounding soil, and tunnels were investigated, which also validated the model's feasibility. Additionally, the deformation and strain response of the subway tunnel under different selection parameters of the enclosing structure and soil were studied. The results showed that, after the foundation pit excavation, the soil inside the pit underwent an uplift, the surrounding soil outside of the pit showed vertical settlement, and the retaining wall created a deformation towards the interior of the pit. Mechanical parameters of plate elements have a small influence on the deformation of metro lines. Axial strain and maximum displacement of the subway tunnel increase with the increase in the soil's Poisson's ratio, and on the contrary, they decrease with the increase in the $\mathrm{m}$-value and $G_{0, \text { ref }}$. The maximum responses of the subway tunnel came from changes to $G_{0, \text { ref }}$ and $v$. These analysis results can be used for the safety evaluation of subway tunnel operation, design, and construction in other similar engineering settings.

\section{Introduction}

Nowadays, with rapid economic development and urban expansion, the construction of subway tunnels has gradually become the most economical and effective method to relieve traffic congestion caused by urbanization progresses. Subway tunnels often cross densely populated areas, where many buildings exist [1]; thus, a common problem is the existence of metro lines in the vicinity of planned foundation pits. Foundation pit excavation is an unloading process that destroys the initial stress state of the surrounding soil and results in the deformation of nearby retaining structures and soil, potentially causing retaining wall lean, uplift at the bottom of a pit, and the settlement of the soil behind the wall. In addition, changes to the soil may somewhat affect subway tunnels adjacent to foundation pit excavation. If the deformation caused by the pit is over the control standard, it will generate risk to the subway operation. Therefore, carrying out a study on the impact of adjacent foundation pit excavation on existing subway tunnels is of great importance for metro safety evaluation.

In recent years, many studies on subway tunnel deformation caused by adjacent foundation pit excavation have been carried out, and many results have been obtained [2-5]; the main research methods are theoretical investigation $[6,7]$ and numerical simulation [8-10] using finite element software. Shil et al. [11] verified that the finite element method is a feasible tool to investigate the excavation stages and to study the influences on existing tunnels induced by deep excavations. Shang et al. [12] proposed a model and derived a theoretical calculation formula to study the effects of excavation in the vicinity of an operational shield tunnel on the forces in the tunnel tube sheet. Shi et al. [13] established a new unloading model, which can take the deformation of the retaining structure and the space effect generated during the pit excavation into consideration. $\mathrm{Li}$ 
et al. [14] investigated different factors' influence on the deformation of the metro line, including subway tunnel buried depth, the excavation width and depth, and the horizontal distance between the foundation pit and the tunnel.

However, a sufficient understanding of the influence of plate element parameters for simulating the envelope structures and soil parameters during excavation on subway tunnels' deformation is still lacking. In this study, a 3D finite element model was established using the simulation software Plaxis 3D based on practical engineering. After validating the model's accuracy, we investigated the deformation response of the existing subway tunnel due to the adjacent foundation pit excavation through simulations using different parameters. The analysis results can provide a valuable reference for relevant engineering design and simulation applications.

\section{Engineering Situation}

2.1. Engineering Background. The project site is located in the Qingguoxiang historical and cultural district in Changzhou city, Jiangsu Provence, China. The proposed project is a two-story hotel with a two-story basement. The excavation area of the foundation pit is approximately $3300 \mathrm{~m}^{2}$, and the excavation depth is about $10.50 \mathrm{~m}$. Both the southern and the western sides of the foundation pit are adjacent to existing historically protected buildings, and the nearest distance between Shi liang's former residence and the pit is $4.6 \mathrm{~m}$. Heping North Road is located on the eastern side of the construction site, and the subway tunnel of line 1 is below the road. The support system scheme of the foundation pit engineering adopts a wall of row piles and one horizontal concrete inner support system. The inner support is set to $-1.5 \mathrm{~m}$, and high-pressure rotary jet piles are used as the water-stopping curtains. The internal support columns are lattice columns, their upper part is lattice steel, and their lower part is a concrete infill pile. A foundation pit support cross section view is shown in Figure 1.

The relationship between the positions of the foundation pit and the subway tunnel is worth noting. The top burial depth of the subway tunnel is approximately $16.0 \mathrm{~m}$, and the tunnel diameter is $6.2 \mathrm{~m}$. The closest distance from the closest subway tunnel line to the support structure is about $13.0 \mathrm{~m}$, and the center distance between the two subway tunnel lines is $14.0 \mathrm{~m}$. The project is within the control region of metro line one (within 50 meters). According to the relevant controlling standard, the maximum vertical and horizontal displacements of the tunnel are required not to surpass $20.0 \mathrm{~mm}$. Thus, it is of vital importance to carry out a safety assessment in order to guarantee the rail transit's secure operation.

2.2. Hydrogeological Condition. Soil layers with similar properties were combined. For the Hardening Soil Model with Small Strain Stiffness, relevant parameters of the soil layers, shown in Table 1, were obtained from triaxial consolidation drained tests, triaxial loading-unloading tests, standard oedometer tests, and resonant column tests. The project site's groundwater mainly consists of upper-layer perched water and pressure-bearing water. Additionally, silty sand makes up a thicker soil layer. The permeability coefficient of each soil layer is displayed in Table 2. The perched water is contained in the miscellaneous fill and the upper clay soil, and it mainly comes from atmospheric precipitation. The silty sand and silty clay layers contain pressure-bearing water. During the investigation, the water level was approximately $-2.42 \sim-3.74 \mathrm{~m}$.

\section{Establishing the Three-Dimensional Finite Element Model}

3.1. Calculation Model. Foundation pit excavation is a typical space problem, though it is often simplified as a plane strain problem in practical design $[15,16]$. During the excavation process, the soil will continuously be unloaded and the stress of the soil will be constantly distributed. Selecting a suitable soil constitutive model plays a vital role in determining the fit of the simulation results to the field data. Considering the nonlinear relation between the stiffness and the dynamic shear modulus of the soil under work load $[17,18]$, the finite element software Plaxis 3D and the Hardening Soil Model with Small Strain Stiffness (HSS model) were used to analyze the project. To minimize the boundary effects, according to existing study results $[19,20]$, the model dimensions were set to $300 \mathrm{~m} * 300 \mathrm{~m} * 40 \mathrm{~m}$. The basic soil elements of the 3D finite element mesh are the 10-node tetrahedral elements. After meshing, the finite element model generated a total of 120,682 elements and 182,509 nodes.

A linear elastic model was adopted to simulate other foundation pit support structures and the subway tunnel: according to the principle of stiffness equivalence, six-node plate elements were used to simulate the retaining structure (including the wall of row piles and the triaxial mixing piles) and the subway tunnel (Table 3), whereas for the inner support structure we used three-node beam elements. The parameters are shown in Table 4. Moreover, 12-node interface elements were used to simulate soil-structure interaction behavior.

3.2. Calculation Sequence. To better fit the reality, the calculation sequence of the simulation was identical to the actual construction steps. Initially, the initial stress field was generated based on the "K0 process." Before starting construction, the existing building structures and the adjacent subway tunnel should be taken into account; these structures have existed there for a long time, which makes the soil stress state stable. Thus, in sequence 2 , the displacement should be reset to zero. The construction of the foundation pit begins from sequence 3 . Table 5 details the specific calculation sequence.

\section{Model Validation}

4.1. Total Deformation of the Model. Figure 2 displays the total deformation of the foundation pit when it is excavated to $-10.5 \mathrm{~m}$; this is mainly due to the stress redistribution 

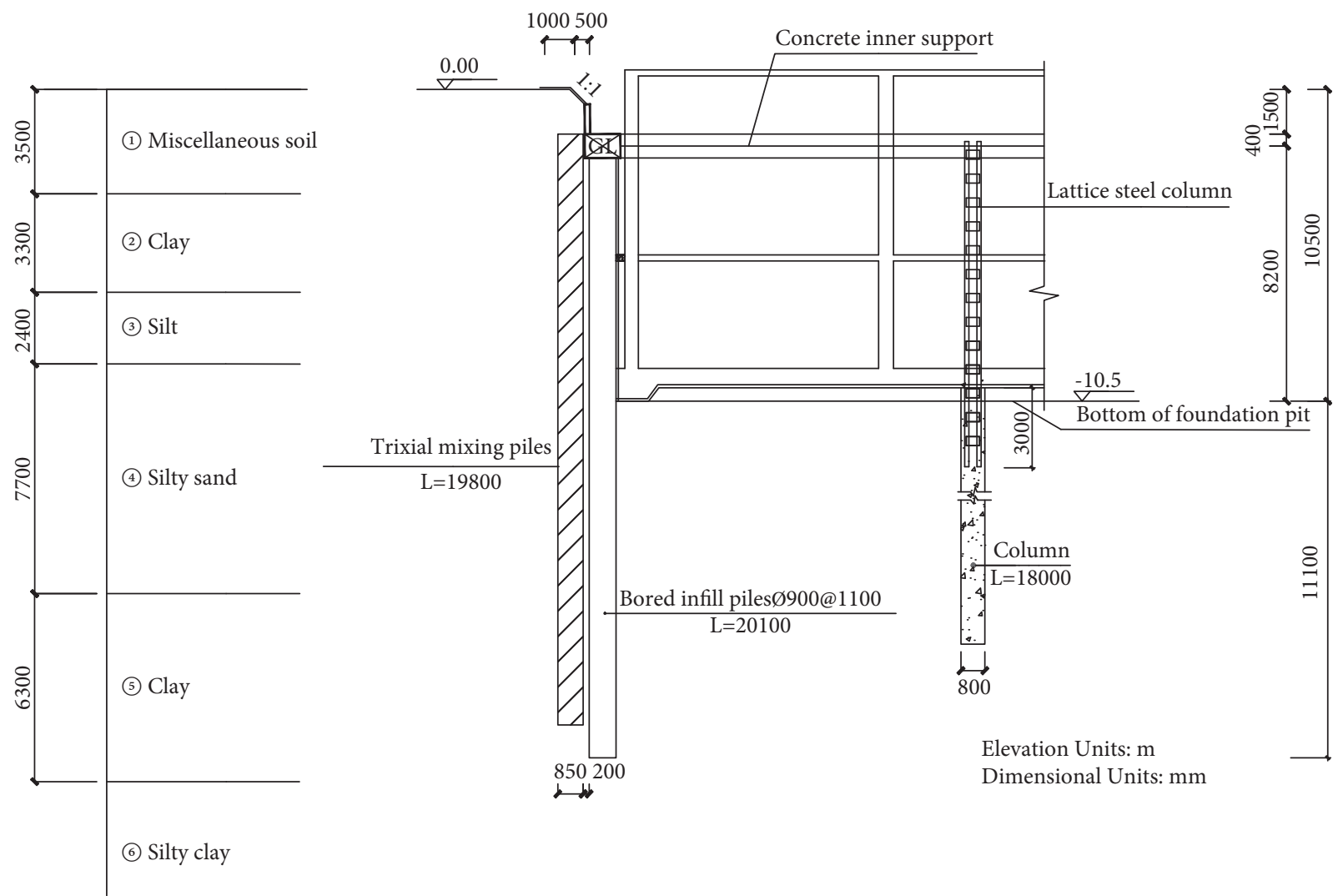

Figure 1: Cross section view of the foundation pit support structure.

TABle 1: Soil parameters.

\begin{tabular}{lccccccccccccc}
\hline Soil layer & $c^{\prime}(\mathrm{KPa})$ & $\varphi^{\prime}\left(^{\circ}\right)$ & $k_{0}$ & $\psi\left(^{\circ}\right)$ & $m$ & $p_{\text {ref }}(\mathrm{KPa})$ & $v_{u r}$ & $E_{50}^{\text {ref }}(\mathrm{MPa})$ & $E_{u r}^{\text {ref }}(\mathrm{MPa})$ & $E_{\text {oe } d}^{\text {ref }}(\mathrm{MPa})$ & $R_{f}$ & $G_{0}^{\text {ref }}(\mathrm{MPa})$ & $\gamma_{0.7}(e-4)$ \\
\hline Clay & 9.13 & 29.50 & 0.51 & 0 & 0.8 & 100 & 0.2 & 4.98 & 42.90 & 4.36 & 0.69 & 54.53 & 4.24 \\
Silt & 18.24 & 34.00 & 0.44 & 4 & 0.62 & 100 & 0.2 & 5.54 & 31.70 & 5.10 & 0.65 & 73.08 & 2.67 \\
Silty sand & 5.28 & 32.52 & 0.46 & 2.52 & 0.66 & 100 & 0.2 & 11.02 & 47.36 & 6.40 & 0.91 & 62.76 & 3.12 \\
Clay & 26.81 & 26.40 & 0.56 & 0 & 0.8 & 100 & 0.2 & 7.62 & 29.70 & 6.03 & 0.62 & 34.56 & 4.81 \\
Silty clay & 13.38 & 26.40 & 0.72 & 0 & 0.75 & 100 & 0.2 & 10.75 & 37.69 & 6.40 & 0.76 & 25.20 & 3.99 \\
\hline
\end{tabular}

Table 2: Permeability coefficient.

\begin{tabular}{lc}
\hline Soil layer & Permeability coefficient $\left(\mathrm{cm} \cdot \mathrm{s}^{-1}\right)$ \\
\hline Clay & $2.0 e-7$ \\
Silt & $2.9 e-3$ \\
Silty sand & $2.9 e-3$ \\
Clay & $2.0 e-7$ \\
Silty clay & $6.0 e-7$ \\
\hline
\end{tabular}

TABle 3: Parameters of plate elements.

\begin{tabular}{lccc}
\hline Parameter & Enclosure pile & Subway tunnel & Unit \\
\hline Thickness, $d$ & 1.0 & 0.35 & $\mathrm{~m}$ \\
Unit weight, $\Upsilon$ & 25.5 & 22.5 & $\mathrm{kN} \cdot \mathrm{m}^{-3}$ \\
Material properties & Isotropic & Isotropic & - \\
Elastic modulus, $E$ & $33.5 e 6$ & $34.5 e 6$ & $\mathrm{kN} \cdot \mathrm{m}^{-2}$ \\
Poisson's ratio, $v$ & 0.2 & 0.2 & - \\
\hline
\end{tabular}

after the stable soil stress state effect has been broken. Also, it can be seen that the pit has an obvious spatial effect: the deformation at the corner of the row pile wall is smaller than
TABle 4: Parameters of beam elements.

\begin{tabular}{lcccc}
\hline Parameters & Top beam & Inner support & $\begin{array}{c}\text { Lattice } \\
\text { steel } \\
\text { column }\end{array}$ & $\begin{array}{c}\text { Concrete } \\
\text { column }\end{array}$ \\
\hline $\begin{array}{l}\text { Elastic modulus } \\
\left(\mathrm{kN} \cdot \mathrm{m}^{-2}\right)\end{array}$ & $3 \mathrm{e} 7$ & $3 \mathrm{e} 7$ & $2.06 e 8$ & $3.15 e 7$ \\
$\begin{array}{l}\text { Unit weight } \\
\left(\mathrm{kN} \cdot \mathrm{m}^{-3}\right)\end{array}$ & 22.5 & 22.5 & 78.5 & 25 \\
Dimension $(\mathrm{m})$ & $0.8^{*} 1.2$ & $0.8^{*} 1.0$ & $D=0.6$ & $D=0.8$ \\
\hline
\end{tabular}

that in the middle region. Thus, the three-dimensional simulation method is a more reasonable way to analyze the complex shape of the foundation pit. The total displacement is $30.47 \mathrm{~mm}$, and the maximum deformation is the vertical uplift at the bottom of the foundation pit (up to $25.22 \mathrm{~mm}$ ). The deformation cloud map and the vector diagram of the west-east directional section when the foundation pit has been excavated to the bottom are shown in Figure 3. As shown in Figure 3(a), the model boundary effect is close to 
TABLE 5: Specific calculation steps.

\begin{tabular}{lc}
\hline Sequence & Construction sequence \\
\hline 1 & Generate the initial stress field \\
2 & Generate existing subway tunnel and buildings; reset displacement to zero \\
3 & Construct support piles \\
4 & Excavation to $-0.5 \mathrm{~m}$; slope support \\
6 & Excavation to $-1.9 \mathrm{~m}$; construct retaining wall \\
7 & Construction of the inner support system \\
8 & Precipitation to $-11 \mathrm{~m}$ \\
\hline
\end{tabular}

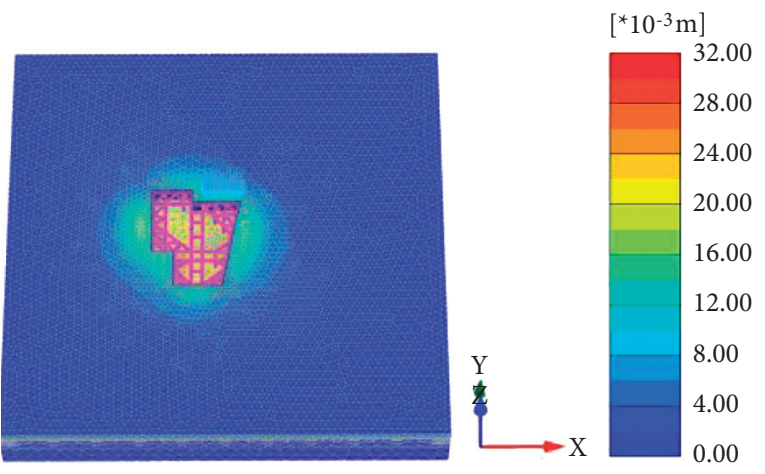

Figure 2: Total displacement of the foundation pit.
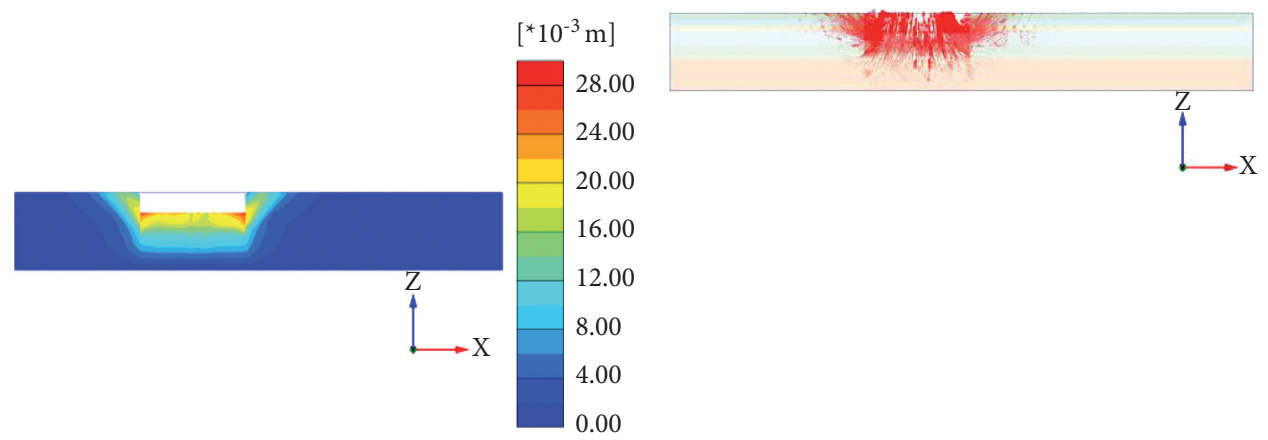

(a)

(b)

FIgURE 3: Deformation of west-east directional section: (a) cloud map; (b) vector diagram.

zero, and analyzing (a) combined with Figure 3(b), it can clearly be seen that the displacement direction is towards the inside of the foundation pit, reaching its maximum at the side wall.

4.2. Lateral Displacement of the Enclosure Pile. The lateral displacement reached its maximum when the foundation pit is excavated to the bottom, and the maximum deformation value happened near the excavation surface. Figure 4 shows the lateral deformation condition of the enclosure pile when the foundation pit was excavated down to $-10.5 \mathrm{~m}$. It is clear that displacement of the long side supporting structure was larger than that of the short side, which is the side of the existing building. The structure's maximum displacement near the side of subway tunnel line 1 was $21.2 \mathrm{~mm}$, and the maximum displacement on the side of Shi Liang's former residence reached $19.4 \mathrm{~mm}$. Additionally, it can be seen from Figure 4 that the structure deformation near the negative corner of the foundation pit was smaller than at the middle region of the supporting structure, and conversely, the positive corner's displacement was larger. This indicates that the negative corner can inhibit deformation and the positive corner can facilitate deformation. A comparison of the simulation results based on the HSS model and the field data of a series of monitor points on the side near the subway tunnel is shown in Figure 5, from which one can consider the established model to be reasonable.

4.3. Vertical Deformation of Soil. As the pit excavation depth increased, the vertical deformation of the soil increased, and the maximum value appeared at $-10.5 \mathrm{~m}$ excavation. Figure 6 shows the simulation and monitor vertical 


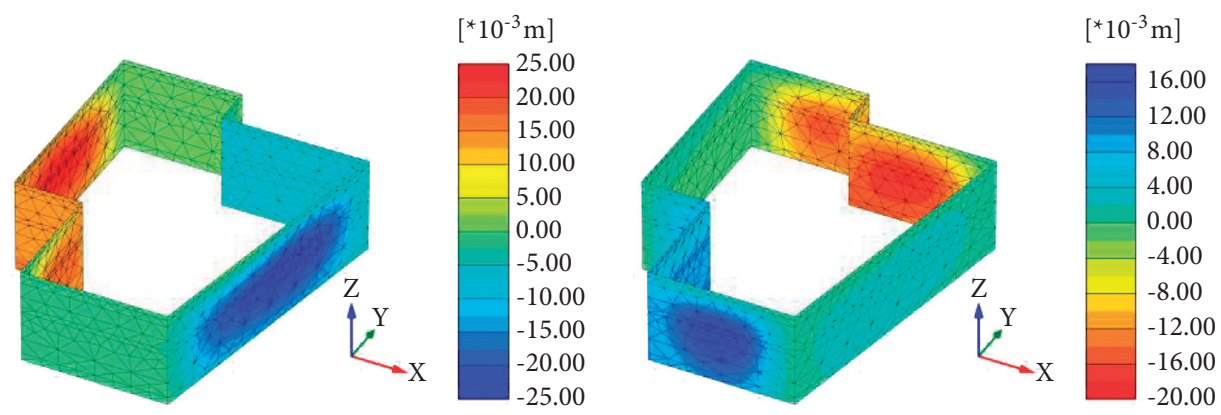

FIGURE 4: Horizontal deformation of the enclosure structure.

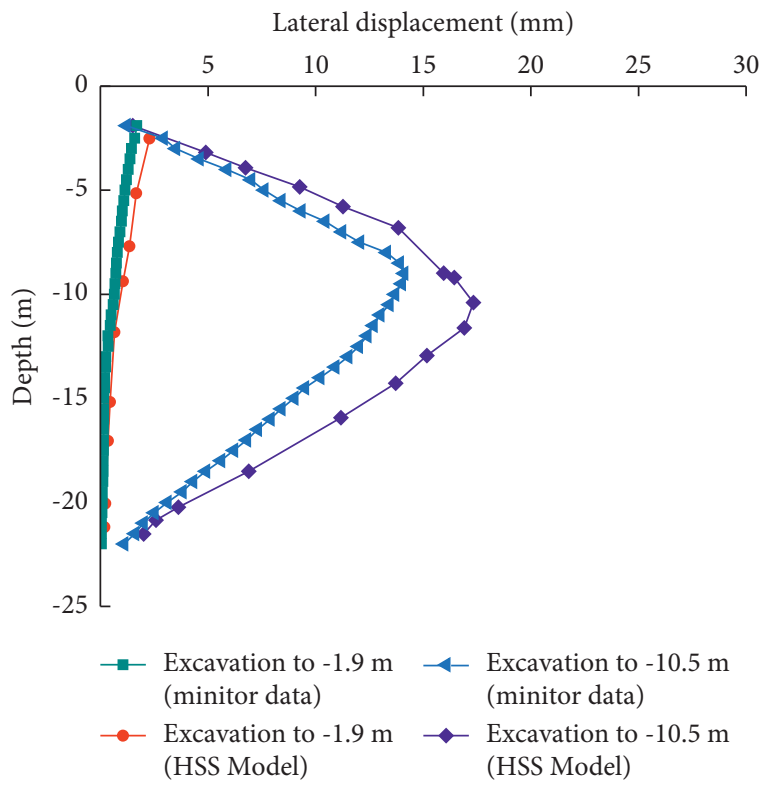

FIGURE 5: Lateral displacement of the retaining wall for the HSS model and monitor data.

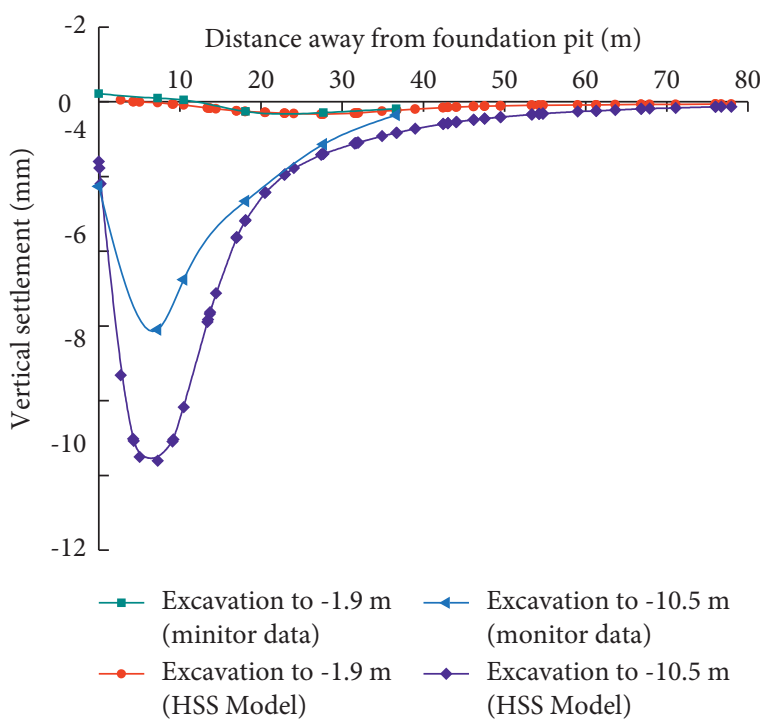

FIGURE 6: Vertical settlement of the surrounding soil for HSS model and monitor data. settlement situation for each of the main construction steps. The entire retaining structure is directed towards the inside of the pit, the reason being that when the inside soil is excavated, under the effect of the internal support, the enclosure structure can be simplified as a statically indeterminate beam. Concurrently, due to soil and water pressure and the lateral thrust on the free side due to the excavation height difference, the style of the deformation appeared.

As can be seen, the numerical simulation results are in good agreement with the actual values, which validates the finite element model. Based on this conclusion, a study on subway tunnel deformation under the influence of different factors was carried out.

\section{Influence on the Subway Tunnel Caused by the Foundation Pit Excavation}

The total displacement diagram of the subway tunnel when the foundation pit was excavated to its bottom is shown in Figure 7. It can be seen that the deformation direction of the left and right lines was similar: in the vertical direction, there mainly was settlement, and in the horizontal direction, the deformation was directed towards the foundation pit. The displacements of the subway tunnel's left and right lines when the foundation pit was excavated to $-1.9 \mathrm{~m}$ are shown in Table 6 . The maximum displacement of the left line was $3.67 \mathrm{~mm}$, of which the vertical maximum settlement was $2.25 \mathrm{~mm}$, and the maximum horizontal displacement was $3.0 \mathrm{~mm}$. The deformation of the right line was smaller than that of left line. The total displacement of the right line was $1.97 \mathrm{~mm}$, of which the vertical settlement was $1.03 \mathrm{~mm}$, and the maximum horizontal displacement was $1.67 \mathrm{~mm}$. It is clear that the pit excavation's influence on the tunnels' horizontal deformation was more pronounced than that on the vertical deformation. The left line's deformation was greater than that of the right line, indicating that the impact level was related to the distance from the foundation pit. Furthermore, from the deformation cloud diagram in Figure 7 , it can also be derived that tunnel deformation was related to the position of the tunnel in relation to the pit site; that is, the maximum deformation of the subway tunnel occurred near the middle of the foundation pit and decreased along the length of the tunnel towards both ends. 


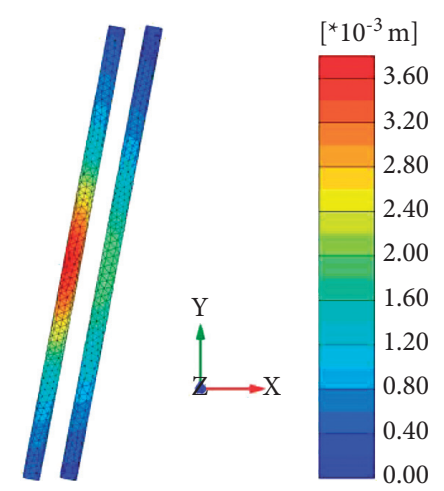

FIgURE 7: Total displacement of subway tunnel.

TABLe 6: Displacement of the subway tunnel.

\begin{tabular}{lcccc}
\hline \multirow{2}{*}{ Sequence } & \multicolumn{2}{c}{ Left line (near the pit) } & \multicolumn{2}{c}{ Right line } \\
& Vertical $(\mathrm{mm})$ & Horizontal $(\mathrm{mm})$ & Vertical $(\mathrm{mm})$ & -0.45 \\
Excavated to $-1.9 \mathrm{~m}$ & -0.52 & -0.25 & -1.03 & -0.12 \\
Excavated to $-10.5 \mathrm{~m}$ & -2.25 & -3.00 & Horizontal $(\mathrm{mm})$ \\
\hline
\end{tabular}

\section{Effect of the Wall of Row Piles}

Plate elements were used to simulate the wall of row piles of the foundation pit's support structures. The effect of the two main parameters, elastic modulus and shear modulus, which can determine the properties of the plate elements, on the deformation of the subway tunnels was investigated by controlling the variables.

6.1. Elastic Modulus Effect. When the shear modulus was $40 \mathrm{MPa}$, the axial strain of each point on the maximum deformation section surface of the subway tunnel's left line is shown in Figure 8. The maximum axial strain appeared at around $120^{\circ}$. From Figure 8 , it can be seen that as the elastic modulus increased, the overall trends of axial strain on the subway tunnel section surface were similar, but the subway tunnel was hardly deformed when the elastic modulus of the wall of row piles increased, which is consistent with a similar study [21].

Figure 9 shows the maximum displacement of the subway tunnel with varying shear modulus. Under the foundation pit soil unloading, vertical and horizontal displacement occurred on the subway tunnel. Vertical deformation consists of settlement and horizontal deformation is directed towards the foundation pit. Taking the left line as an example, with the elastic modulus increasing, the vertical deformation decreased gradually, varying from 2.35 to $2.22 \mathrm{~mm}$; the variation is small, but the horizontal displacement was almost constant. The results showing twodirectional deformation indicate that the vertical displacement of the subway tunnel was more sensitive than the horizontal displacement, and the deformation value was reduced when the plate elements' elastic modulus increased. In general, the effect of the elastic modulus on the existing subway tunnel was extremely small during the excavation of the foundation pit.

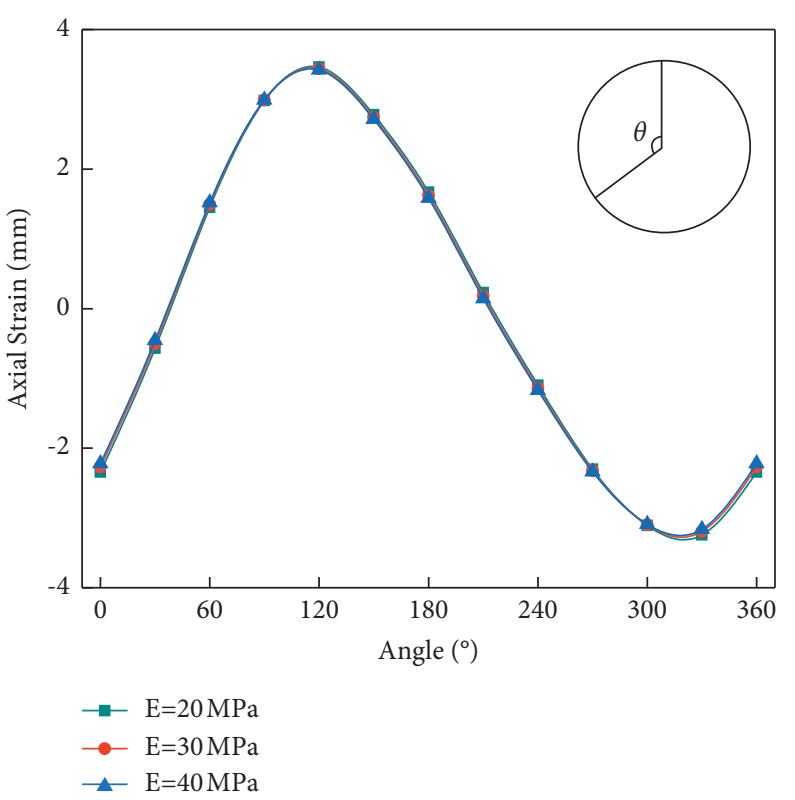

Figure 8: Axial strain of $x-z$ plane under varying elastic modulus.

6.2. Shear Modulus Effect. When the elastic modulus was $30 \mathrm{MPa}$, the responses of the subway tunnel under varying shear modulus are shown in Figure 10. As shown in the figure, the maximum axial strain showed little variation as the shear modulus increased. The simulation results are identical to the conclusion of the study regarding the change of elastic modulus.

Figure 11 shows the maximum displacement diagram of the metro lines. Each direction's displacement variation is very small. Combined with the analysis results of the elastic modulus effect, it can be concluded that the mechanical parameters of the plate elements have a small effect on subway tunnel deformation influenced by the 


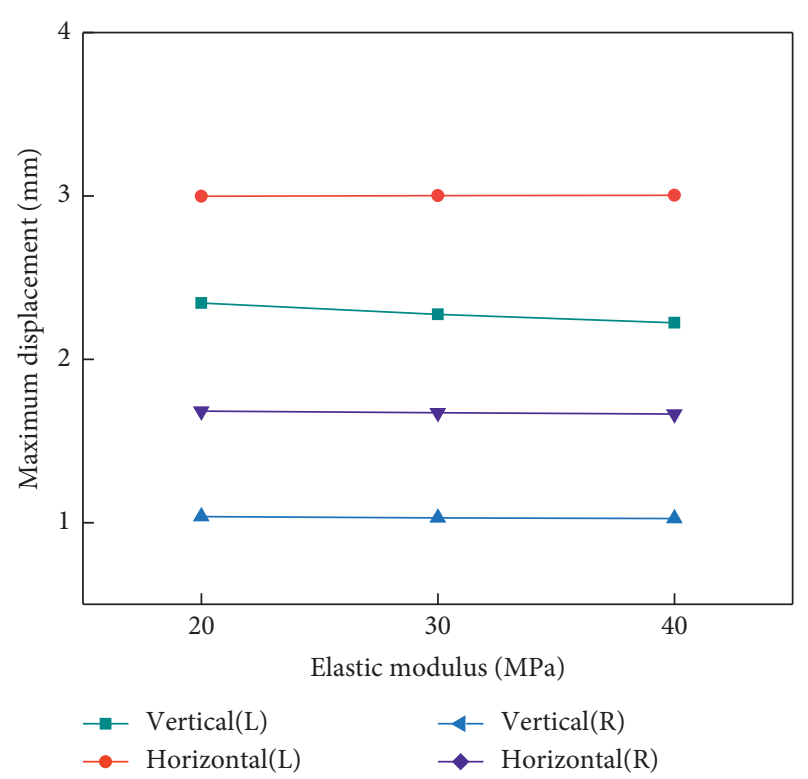

FIGURE 9: Displacements of the subway tunnel under varying elastic modulus.

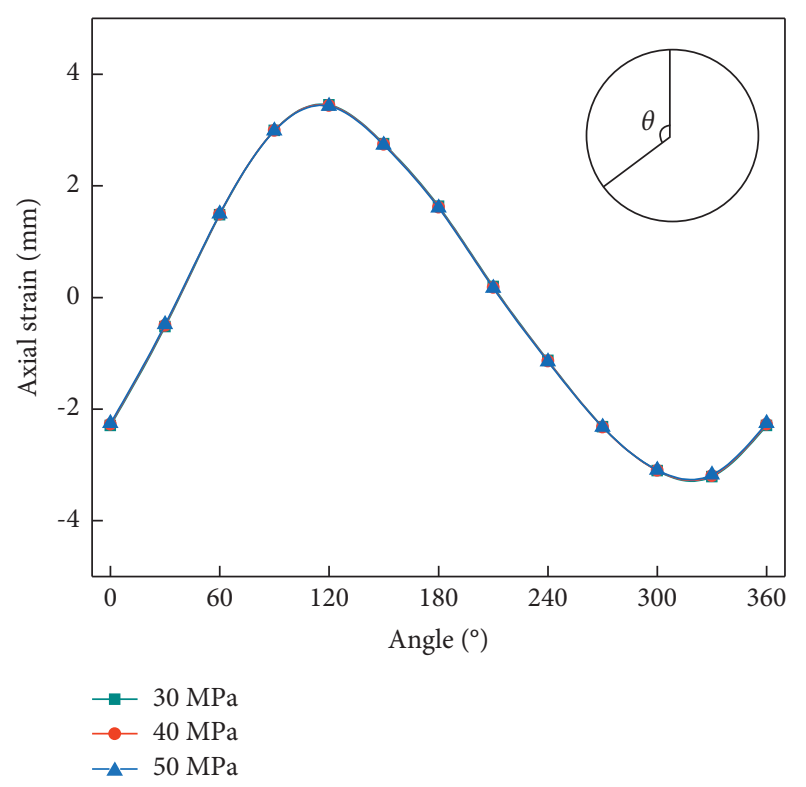

FIGURE 10: Axial strain of $x-z$ plane under varying shear modulus.

adjacent pit excavation, and the overall trend is one of a decrease in deformation with increasing parameter values.

\section{Effects of Soil Parameters}

The foundation pit and the existing subway tunnel are connected by surrounding soil as the connective media. Additionally, the subway tunnel deformation is subjected to the soil stress redistribution during the excavation process. Therefore, surrounding soil parameters have a nonnegligible effect on the deformation of the subway tunnel. Existing study results [22-25] regarding the HSS

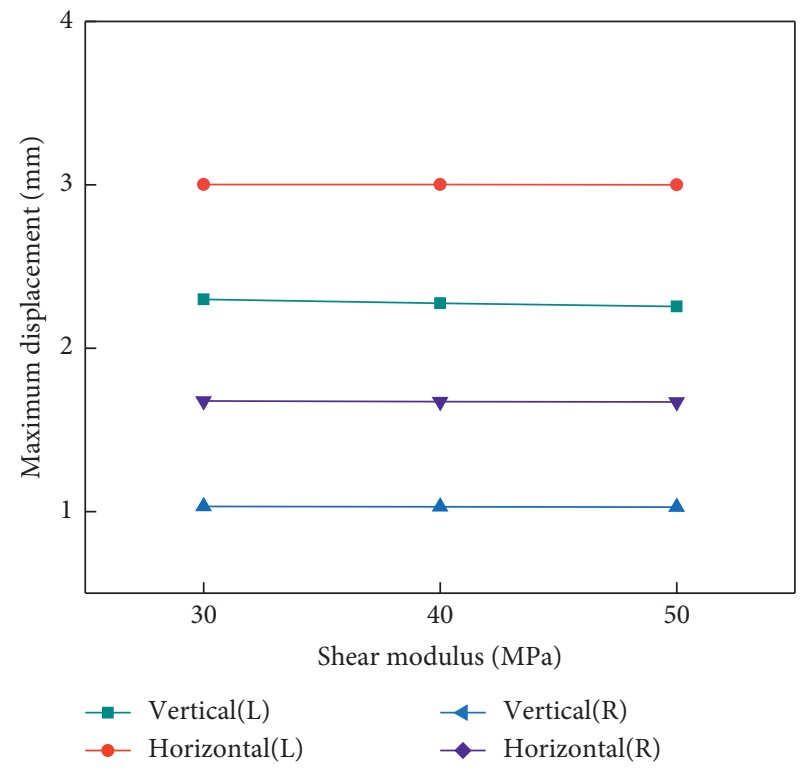

FIgURE 11: Displacements of the subway tunnel under varying shear modulus.

model show that the parameters of power for stress-level dependency of the stiffness $m$ and reference dynamic shear modulus $G_{0, \text { ref }}$ are sensitive when simulating the foundation pit. Meanwhile, Poisson's ratio is a parameter that reflects the size of the transverse deformation of the material. Based on this, take a typical soil in Changzhou City, silty clay, as an example; the study considers the effect of Poisson's ratio $v, m$, and $G_{0, \text { ref }}$.

7.1. Poisson's Ratio of the Soil Effect. Poisson's ratio is a type of elastic constant. In Plaxis 3D, it is usually considered as a default value, which is equal to 0.2 . Brinkgreve [26] proposed that Poisson's ratio when the soil is unloaded is smaller compared with that of the loaded soil. The analysis results of $v$ are $0.1,0.2$, and 0.3 , when $m=0.75$ and $G_{0 \text {,ref }}=70.20 \mathrm{MPa}$, as shown in Figure 12. The maximum axial strain appeared near $120^{\circ}$ and $300^{\circ}$ of the section surface; when $v$ was 0.2 , the maximum value was approximately $6 \mathrm{~mm}$. With Poisson's ratio increasing, the maximum axial strain increases, and the change rate also increases.

Figure 13 shows the two-directional displacement changes of the subway's left and right lines for different Poisson's ratios. As a whole, the deformation direction of the subway tunnel consists of vertical settlement and horizontal orientation towards the pit. It is obvious that the maximum displacement of the subway tunnel's left and right lines increases as Poisson's ratio increases. The vertical total settlement of the left line varies from 1.18 to $1.99 \mathrm{~mm}$, and the variation of the left line's horizontal displacement is about $1.45 \mathrm{~mm}$. The change in both the vertical and horizontal displacements is clear. At the same time, the response of the horizontal displacement of the left line is greater than that of the vertical displacement, and it can be seen from Figure 13 that the effect on the left line, when subjected to excavation and the change of soil parameters, is large. In 


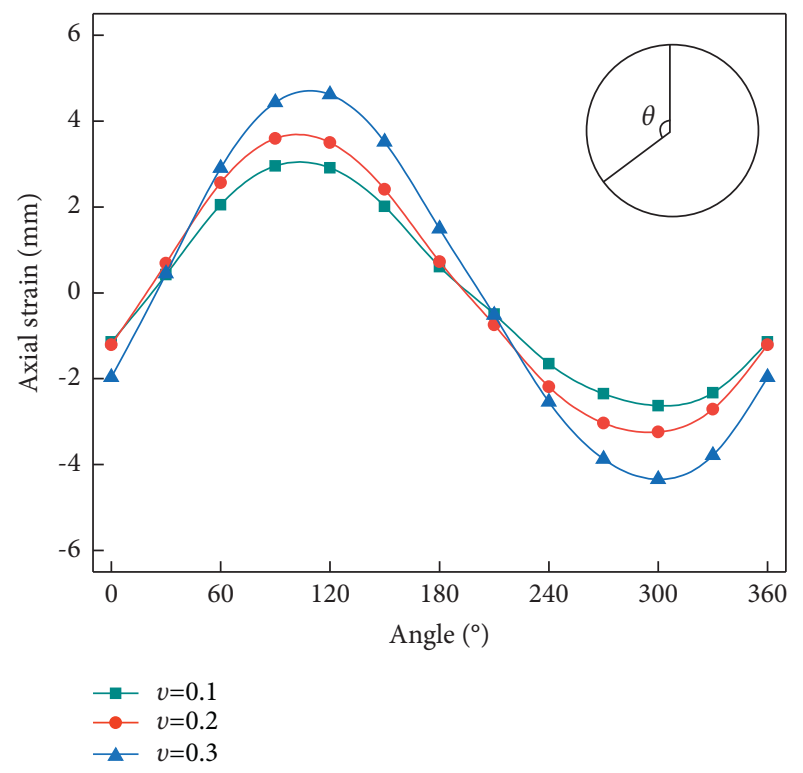

Figure 12: Axial strain of $x-z$ plane under different soil's Poisson's ratios.

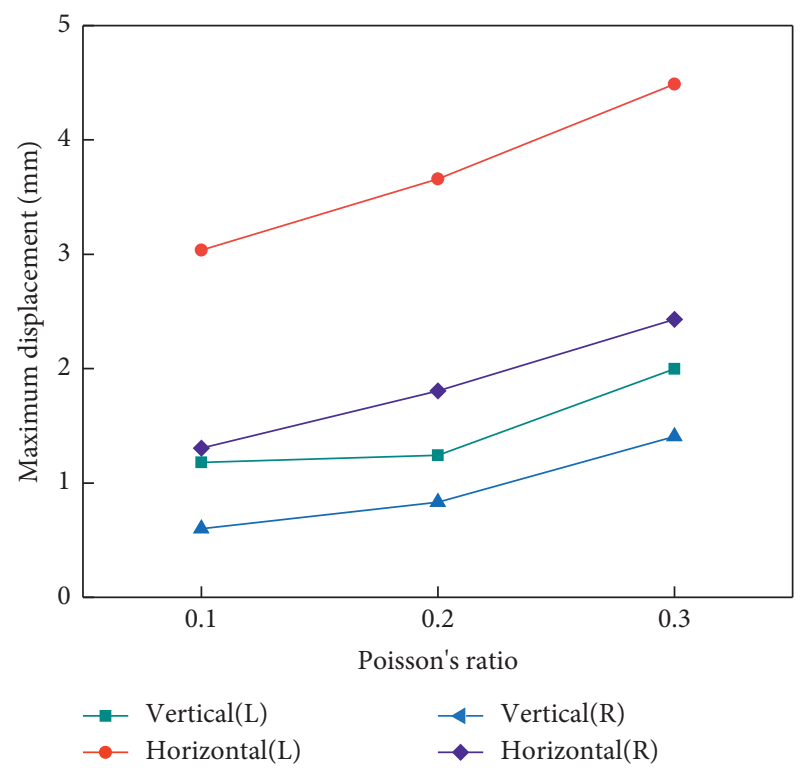

Figure 13: Displacements of the subway tunnel under different soil's Poisson's ratios.

summary, the changes to Poisson's ratio are of great influence when simulating the existing subway tunnel's deformation as affected by adjacent foundation pit engineering.

7.2. M-Value of the Soil Effect. According to the study results of Janbu et al. [27], for clay, the $m$-value varies in the range of $0.5 \sim 1.0$, but Benz [28] set this range as 0.7 0.9. When the soil's Poisson's ratio is 0.2 and $G_{0, \text { ref }}$ was $70.20 \mathrm{MPa}$, the axial strain values of the points on the surface section of the subway tunnel's left line for different $m$-values are shown in Figure 14. As the $m$-value increased, the maximum axial strain showed a certain increase, but the change of strain

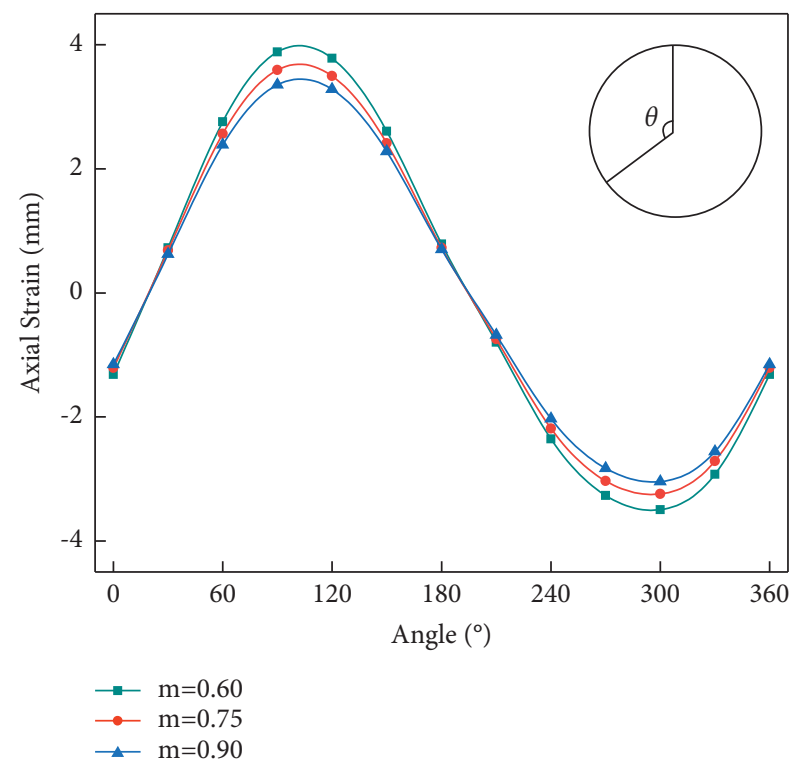

Figure 14: Axial strain of $x$ - $z$ plane under different soil $m$-values.

value was small. Furthermore, the trend of the curve was somewhat steeper.

Figure 15 shows the deformation growing phenomenon of the subway tunnel with the increase in the $m$-value. In the figure, the change in the horizontal displacement and vertical displacement displayed for the left and right lines is small. For the left line, when $\mathrm{m}$ is changed from 0.6 to 0.9 , the slope of the horizontal displacement curve is steeper, and the displacement value decreases with the increase in $m$-value, from 3.95 to $3.42 \mathrm{~mm}$. This can indicate that the sensitivity of the horizontal displacement is larger than that of the vertical displacement, which is opposite to the influence of the elastic modulus of the plate elements. In addition, the horizontal displacement is larger than that of the vertical settlement in both the left and right lines. In total, an increase in the $m$-value can reduce the deformation effect in the subway tunnel caused by pit excavation, but the effect is not large. This is consistent with the results exhibited by the surface section axial strain of the subway tunnel.

7.3. Reference Dynamic Shear Modulus of the Soil Effect. When $v=0.2$ and $m=0.75$, the axial strain curves of different values of the reference dynamic shear modulus $G_{0, \text { ref }}$ of the soil for the points on the surface of the subway tunnel's left line surface section are shown in Figure 16. It is obvious that the maximum axial strain of the tunnel gradually decreases with the increase in the soil's $G_{0, \text { ref }}$ value, and the range of variation is the largest when the $G_{0, \text { ref }}$ value changes from 0.7 to 1.3 .

Figure 17 displays the maximum vertical and horizontal displacements of the subway tunnel's two lines. It can easily be seen that an increase in the $G_{0, \text { ref }}$ value played an effective role in reducing the subway tunnel's deformation for both the left and right lines. Similar to the other simulation results, the left line's deformation is larger than that of the right 


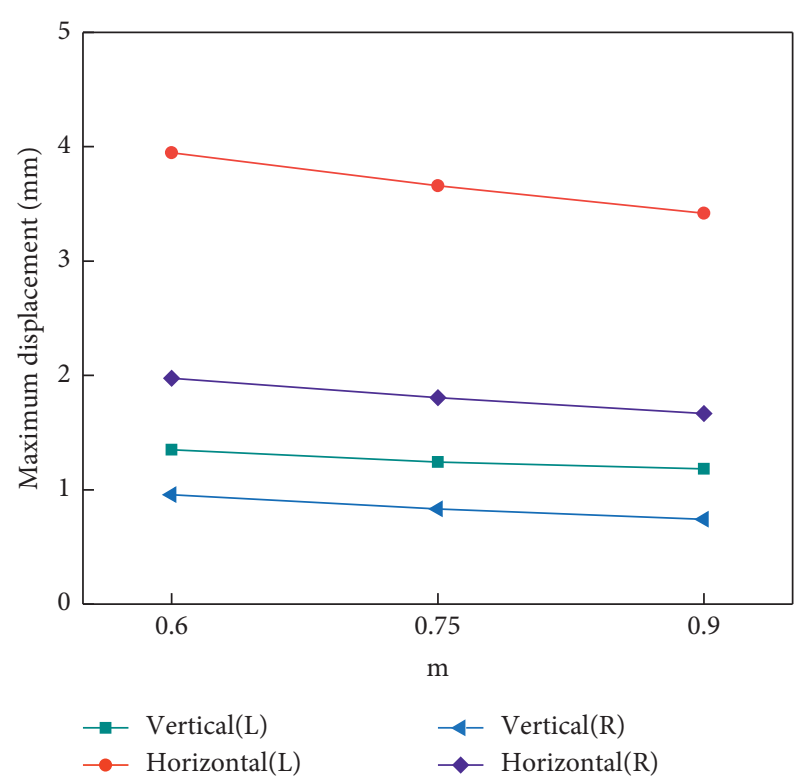

FIgURE 15: Displacements of the subway tunnel under different soil $m$-values.

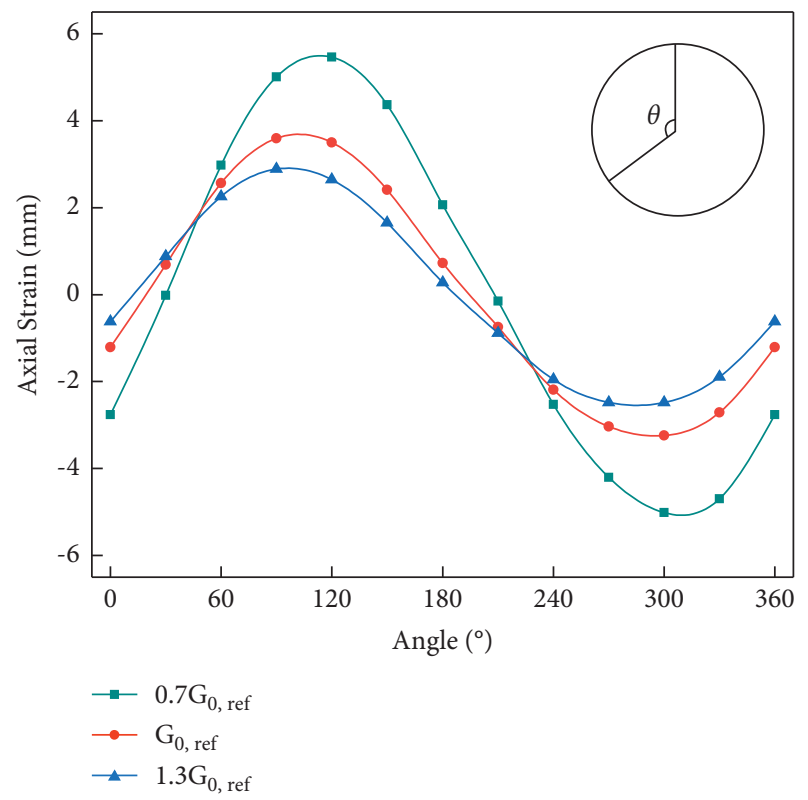

Figure 16: Axial strain of $x-z$ plane under varying soil dynamic shear modulus.

line and the horizontal displacement is also greater than the vertical displacement. For the left line, when comparing between the variations for the vertical and horizontal displacements (Table 7), it can be concluded that, when the $G_{0, \text { ref }}$ value changes from 1.0 to 1.3 , its effect on reducing the deformation of the subway tunnel is larger. In general, the deformation of the subway tunnel decreases when $G_{0, \text { ref }}$ increases, and the effect is obvious. Thus, in engineering practice, the parameter selection of the $G_{0, \text { ref }}$ value when simulating subway tunnel deformation subjected to pit excavation is critical.

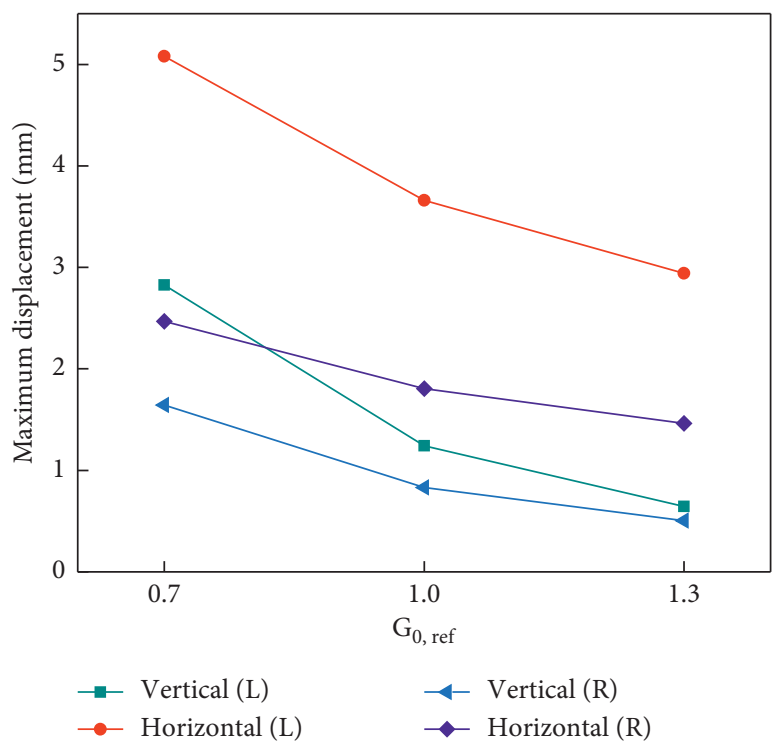

FIGURE 17: Displacements of the subway tunnel under varying soil dynamic shear modulus.

TABle 7: Left metro line displacement.

\begin{tabular}{lcccc}
\hline $\begin{array}{l}G_{0, \text { ref }} \\
\text { value }\end{array}$ & $\begin{array}{c}\text { Vertical } \\
(\mathrm{mm})\end{array}$ & $\begin{array}{c}\text { Horizontal } \\
(\mathrm{mm})\end{array}$ & $\begin{array}{c}\text { Variation } \\
\text { Vertical } \\
(\mathrm{mm})\end{array}$ & $\begin{array}{c}\text { Horizontal } \\
(\mathrm{mm})\end{array}$ \\
\hline $0.7 G_{0, \text { ref }}$ & 1.18 & 3.04 & 0.06 & 0.62 \\
$1.0 G_{0, \text { ref }}$ & 1.24 & 3.66 & 0.76 & 0.83 \\
$1.3 G_{0, \text { ref }}$ & 2.00 & 4.49 & & \\
\hline
\end{tabular}

\section{Conclusions}

The simulation results of the established three-dimensional model using Plaxis 3D software based on the HSS model, compared with field data, demonstrate that the finite element model is valid. The study of the influence of parameter changes of the support structure and soil on the metro lines helps derive better deformation regulations. The specific conclusions are as follows:

(1) During the excavation of the pit, the surrounding soil will redistribute the stress state continuously, which results in the deformation of the sheet row wall and soil, consisting of lateral displacement of the retaining wall directed towards the inside of the pit, soil vertical settlement in the outside of the pit, and uplift in the inside of the foundation pit. The total displacement of the left line (close to the pit) is greater than that of the right line, and the horizontal displacement of each line is larger than the vertical displacement.

(2) The response of the metro line deformation affected by the two mechanical parameters elastic modulus, $E$, and shear modulus, $G$, is minimal, but axial strain and displacement of metro lines still decrease when the two parameters increase.

(3) For the constitutive model parameters, namely, Poisson's ratio, $v$, the $m$-value, and the reference 
dynamic shear modulus $G_{0 \text {,ref }}$, the axial strain and displacement of the subway tunnel in the horizontal and vertical directions increase when the soil's Poisson's ratio increases. On the contrary, they decrease when the $m$-value and $G_{0 \text {,ref }}$ increase. In terms of the range of variation, the subway tunnel responds more to Poisson's ratio and $G_{0 \text {,ref }}$ compared to other parameters.

\section{Data Availability}

The data used in the paper to support the findings are available from the corresponding author upon request.

\section{Conflicts of Interest}

The authors declare that there are no conflicts of interest regarding the publication of this paper.

\section{Acknowledgments}

This work was supported by Changzhou Science and Technology Planning Project (no. CE20209001) and Changzhou Key Research and Development Project (no. CE20219001).

\section{References}

[1] Q. J. Zhang, L. Wu, S. S. Cui, Y. Yu, Z. Zhang, and J. Zhao, "Surface settlement induced by subway tunnel construction based on modified peck formula," Geotechnical \& Geological Engineering, vol. 37, no. 4, p. 13, 2019.

[2] R. Liang, T. Xia, and M. Huang, "Simplified analytical method for evaluating the effects of adjacent excavation on shield tunnel considering the shearing effect," Computers and Geotechnics, vol. 81, pp. 167-187, 2017.

[3] H. S. Sun, Y. D. Chen, J. H. Zhang, and T. H. Kuang, "Analytical investigation of tunnel deformation caused by circular foundation pit excavation," Computers and Geotechnics, vol. 106, pp. 193-198, 2019.

[4] G. Zheng, Y. M. Du, X. S. Cheng, X. Deng, Y. Diao, and F. Wang, "Characteristics and prediction methods for tunnel deformations induced by excavations," Geomechanics and Engineering, vol. 12, no. 3, pp. 361-397, 2017.

[5] F. Y. Meng, R. P. Chen, and X. Kang, "Effects of tunnelinginduced soil disturbance on the post-construction settlement in structured soft soils," Tunnelling and Underground Space Technology, vol. 80, pp. 53-63, 2018.

[6] S. H. Ye, Z. F. Zhao, and D. Q. Wang, "Deformation analysis and safety assessment of existing metro tunnels affected by excavation of a foundation pit," Underground Space, vol. 6, no. $4,2020$.

[7] M. G. Li, J. J. Chen, J. H. Wang, and Y. F. Zhu, "Comparative study of construction methods for deep excavations above shield tunnels," Tunnelling and Underground Space Technology, vol. 71, pp. 329-339, 2018.

[8] G. Wei, X. H. Zhang, X. B. Lin, and X. X. Hua, "Variations of transverse forces on nearby shield tunnel caused by foundation pits excavation," Rock and Soil Mechanics, vol. 41, no. 2, pp. 635-644+54, 2020.

[9] X. H. Zhang, G. Wei, and C. W. Jiang, "The study for longitudinal deformation of adjacent shield tunnel due to foundation pit excavation with consideration of the retaining structure deformation," Symmetry, vol. 12, no. 12, 2020.

[10] X. Wen and C. Pang, "Influence of foundation pit excavation on existing shield tunnel and its protection range," Applied Mechanics and Materials, vol. 3307, pp. 1258-1263, 2014.

[11] J. W. Shi, C. W. W. Ng, and Y. H. Chen, "Three-dimensional numerical parametric study of the influence of basement excavation on existing tunnel," Computers and Geotechnics, vol. 63, pp. 146-158, 2015.

[12] G. W. Shang, S. Li, and C. Zhai, "Monitoring data analysis on deformation correlation between foundation pit and adjacent metro structure," Journal of Disaster Prevention and Mitigation Engineering, vol. 40, no. 1, pp. 107-115, 2020.

[13] J. Shi, C. W. Ng, and Y. Chen, "A simplified method to estimate three-dimensional tunnel responses to basement excavation," Tunnelling and Underground Space Technology, vol. 62, pp. 53-63, 2017.

[14] M. G. Li, X. Xiao, J. H. Wang, and J. J. Chen, "Numerical study on responses of an existing metro line to staged deep excavations," Tunnelling and Underground Space Technology, vol. 85, pp. 268-281, 2019.

[15] L. X. Li, Y. L. Zhang, and X. B. Hu, "Finite element analysis of A pit-in-pit excavation based on PLAXIS 3D," Chinese Journal of Underground Space and Engineering, vol. 12, no. S1, pp. 254-261+66, 2016.

[16] J. T. H. Wu and S. C. Y. Tung, "Determination of model parameters for the hardening soil model," Transportation Infrastructure Geotechnology, vol. 7, no. 1, 2020.

[17] M. Cudny and A. Truty, "Refinement of the Hardening Soil model within the small strain range," Acta Geotechnica, vol. $15,2020$.

[18] V. Sundaravel and G. R. Dodagoudar, "Deformation and stability analyses of hybrid earth retaining structures," International Journal of Geosynthetics and Ground Engineering, vol. 6, no. 3, 2020.

[19] L. D. Zong, Z. H. Xu, and Q. P. Weng, “Application of small strain constitutive model in the analysis of a ultra large and deep excavation," Chinese Journal of Underground Space and Engineering, vol. 15, no. S1, pp. 231-242, 2019.

[20] F. Y. Liang, Y. J. Jia, Y. J. Ding, and M. S. Huang, "Experimental study on parameters of HSS model for soft soils in Shanghai," Chinese Journal of Geotechnical Engineering, vol. 39, no. 2, pp. 269-278, 2017.

[21] J. Zhang, R. Xie, and H. Zhang, "Mechanical response analysis of the buried pipeline due to adjacent foundation pit excavation," Tunnelling and Underground Space Technology, vol. 78, pp. 135-145, 2018.

[22] S. Likitlersuang, S. Teachavorasinskun, C. Surarak, E. Oh, and A. Balasubramaniam, "Small strain stiffness and stiffness degradation curve of Bangkok Clays," Soils and Foundations, vol. 53, no. 4, pp. 498-509, 2013.

[23] B. C. B. Hsiung and S. D. Dao, "Evaluation of constitutive soil models for predicting movements caused by a deep excavation in sands," Electronic Journal of Geotechnical Engineering, vol. 19, Article ID 17344, 2014.

[24] Y. Z. Shi, J. C. Ruan, and C. X. Wu, "Xiamen area typical stratum of HS-small model for small strain parameters sensitivity analysis," Science Technology and Engineering, vol. 17, no. 2, pp. 100-105, 2017.

[25] X. C. Dong, S. L. Wang, and M. W. Guo, "Parameter optimization of HSS model based on compression test curves," Rock and Soil Mechanics, vol. 41, no. S2, pp. 1-9, 2020.

[26] R. B. J. Brinkgreve, "Selection of soil models and parameters for geotechnical engineering application," in Proceedings of 
the Geo-Frontiers Congress, Austin, TX, United States, January 2005.

[27] J. Janbu, "Soil compressibility as determined by oedometer and triaxial tests," in Proceedings of the 3rd European Conference on Soil Mechanics and Foundation Engineering, Wiesbaden, Germany, October 1963.

[28] T. Benz, Small-strain Stiffness of Soils and its Numerical Consequences, Institute of Geotechnical Engineering, University of Stuttgart, Stuttgart, Germany, 2007. 